\title{
Protestantismo no norte goiano: estudo sobre a viagem de Archibald Macintyre (1920)
}

\section{Protestantism in the North of Goiás: study about the trip of Archibald Macintyre (1920)}

\author{
Ordália Cristina Gonçalves Araújo*
}

\begin{abstract}
Resumo
Este artigo analisa o relato de viagem de Archibald Macintyre - Descendo o rio Araguaia - redigido quando o mesmo excursionou pelo norte de Goiás em 1920 no intuito de averiguar as possibilidades de implantação do protestantismo por estas regiões, incluindo as sociedades indígenas. Investigar este relato de viagem como uma fonte histórica produzida por um missionário protestante ao projetar seu olhar estrangeiro, eurocentrado e civilizador para o norte goiano na primeira metade do século passado insere-se no contexto historiográfico brasileiro no qual se observa uma tendência crescente do uso deste tipo de material - como fontes documentais e objeto de estudo - em trabalhos acadêmicos cuja diversificação em relação aos enfoques temáticos e às abordagens teóricas resultam numa ampla produção historiográfica. Por outro lado, contribui para as pesquisas sobre a história regional, principalmente aquelas relacionadas ao protestantismo no estado de Goiás.
\end{abstract}

Palavras chave: Relato de viagem; protestantismo; norte goiano.

\begin{abstract}
This article analyzes the travel writing of Archibald Macintyre - Down the Araguaya - written while he toured the North of Goiás, in 1920, aiming to investigate the possibilities of the introduction of Protestantism in those regions, including indigenous societies. To investigate this travel writing as a historical source produced by a protestant missionary projecting his foreign, euro centered and civilizing look to Northern Goiás in the first half of the last century, is included in the Brazilian historiographical context in which there is a growing trend to use this type of material - such as documentary sources and study objects - in scholar papers whose diversification in relation to the thematic approaches and theoretical approaches results in extensive
\end{abstract}

\footnotetext{
*Doutoranda do Programa de Pós-Graduação de História da Universidade Federal de Goiás. Professora de Didática e Metodologia de Ensino de História da Universidade Estadual de Goiás. E-mail: ordalia_c@ hotmail.com
} 
historiography. On the other hand, it contributes to research about regional history, especially that related to Protestantism in the state of Goiás.

Keywords: Travel writing; protestantism; Northern Goiás

\section{Introdução}

O artigo em pauta constitui-se da análise do relato de viagem Descendo o Rio Araguaia (Down the Araguaya) de Archie Macintyre. Aborda uma excursão feita pelo autor por volta de 1920, na região do então norte de Goiás, atual Tocantins. A análise, centrada no relato de viagem como um corpus documental heterogêneo, ${ }^{1}$ visa, primordialmente, contribuir com os estudos relacionados à expansão do protestantismo de missão em Goiás.

Investigar a obra de Macintyre insere-se no contexto historiográfico brasileiro no qual se observa uma tendência crescente do uso de relatos de viagem - como fontes documentais e objeto de estudo - em trabalhos acadêmicos dando "origem a uma produção volumosa, além de variada do ponto de vista dos enfoques temáticos e das abordagens teóricas"3. Desde a fundação do Instituto Histórico e Geográfico Brasileiro (IHGB) até a escrita de obras "clássicas" da história do Brasil (Capistrano de Abreu - Capitulos de história colonial; Sérgio Buarque de Holanda - Raízes do Brasil, História geral da civilização brasileira, dentre outras), os relatos de viagem tiveram espaço na produção historiográfica brasileira.

Atualmente, os trabalhos com esses corpora documentais têm sido motivados, entre os historiadores, por questões que envolvem "a discussão sobre as intencionalidades evidenciadas nas entrelinhas do discurso dos viajantes, o lugar de enunciação - nacional, social e ideológico - do porta-voz daquele

\footnotetext{
${ }^{1}$ JUNQUEIRA, Mary Anne. Elementos para uma discussão metodológica dos relatos de viagem como fonte para o historiador. In: JUNQUEIRA, M. A; FRANCO, S. M. (Orgs) Cadernos de Seminários de Pesquisa. São Paulo: Departamento de História da Faculdade de Filosofia, Letras e Ciências Humanas. Universidade de São Paulo/Humanitas, 2011, p. 46.

${ }^{2}$ Expressão utilizada para se referir ao protestantismo inserido no Brasil como resultado da atividade missionária de diversos agentes protestantes e suas respectivas denominações oriundos dos Estados Unidos e Inglaterra, tais como os congregacionais, presbiterianos, metodistas, batistas e adventistas. DREHER, Martin N. Protestantismos na América Meridional. In: DREHER, Martin N. (Org). 500 anos de Brasil e Igreja na América Meridional. Porto Alegre, EST Edições, 2002, p. 115-138.

${ }^{3}$ FRANCO, Stella Maris Scatena. Relatos de viagem: reflexões sobre seu uso como fonte documental. In: JUNQUEIRA, M. A; FRANCO, S. M. (Orgs). op. cit. , p. 62.
} 
discurso ou os interesses particulares que mobilizaram suas representações". ${ }^{4}$ O que significa privilegiar um enfoque "quase que exclusivo sobre os viajantes e seus relatos", abordagem que adotamos nesta análise ao problematizar o autor - Archibald Macintyre - e sua prática, no contexto histórico do norte goiano no início do século XX, visto que "os relatos de viagens representam para o investigador contemporâneo um rico manancial como fontes documentais para a atividade historiográfica". ${ }^{5}$

O relato dessa viagem se encaixa no gênero textual híbrido dado os diversos discursos embutidos na sua escrita sejam eles religiosos, políticos, historiográficos, etnográficos, dentre outros, que permitem vislumbrar o ideário da época, expresso pela prática discursiva do missionário quando alia propagação religiosa com ideais de "civilização" e "progresso".

No que se refere ao aporte teórico, o artigo é elaborado com base na epistemologia ecológica do antropólogo Timothy Ingold. As epistemologias ecológicas dizem respeito a um campo epistêmico plural que emerge no pensamento contemporâneo no contexto de crise da racionalidade moderna ao convergir epistemologias distintas que buscam nas referências ecológicas a estruturação das suas formas de pensar e conhecer. Uma delas é a psicologia ecológica de Tim Ingold que considera o engajamento no mundo (ou ambiente) como uma condição para o conhecimento visto que é no mundo que o observador é atravessado por fluxos de luz, sons e texturas dando-lhes a possibilidade de compreendê-lo. Conhecer, neste caso,

é fundamentalmente uma habilidade que adquirimos na relação com outros organismos e seres que habitam o mesmo mundo, e não uma prerrogativa humana que se processaria no espaço restrito da mente como uma operação racional. Torna-se, assim, impossível dissociar a mente do corpo, a cultura da natureza, o conhecimento da experiência. ${ }^{6}$

Desta forma, Ingold critica contundentemente os modelos da psicologia cognitivista e a teoria representacionista de base antropocêntrica das ciências sociais e postula uma teoria do conhecimento ancorada no engajamento pessoal e na simetria dos organismos que habitam o mundo. Um conhecimento que se adquire por meio de habilidades desenvolvidas a partir da educação da atenção. Vista como uma via privilegiada para o conhecimento, Ingold

\footnotetext{
${ }^{4}$ Ibidem, p. 71.

${ }^{5}$ MONTEZ, Luiz Barros. Relatos de viagens como objetos de reflexão historiográfica e da prática tradutória. Cad. Trad., Florianópolis, nº especial, p. 277-298, jul./dez. 2014, p. 282.

${ }^{6}$ STEIL, Carlos Alberto; CARVALHO, Isabel Cristina de Moura. Epistemologias ecológicas: delimitando um conceito. Mana. Estudos de Antropologia Social. 20(1): 163-183, 2014, p. 164.
} 
aproxima de James Gibson para afirmar que a educação da atenção e o aprender são equivalentes na psicologia ecológica pois reconhece "a percepção como uma atividade de um organismo num ambiente, em vez de uma mente dentro de um corpo"?

Postas estas considerações, elaboramos o artigo em três momentos.

Na primeira problematizamos a atividade missionária de Macintyre em interlocução com o contexto histórico da época, bem como a obra em si cujas intenções não ficaram restritas ao período da excursão pelo norte do Goiás mas extrapolou as fronteiras religiosas ao ser utilizada como subsídio ao conhecimento etnográfico dos povos indígenas do Vale do Araguaia.

Em seguida, demonstramos como essa região, incluindo os Karajá como seus habitantes imemoriais, constituíram-se em alvos de projetos civilizacionais, dentre eles, o de integrar os povos indígenas à sociedade envolvente com a política de formação de intérpretes indígenas ao contexto nacional (no período imperial) e com as intenções protestantizadoras das agências missionárias (no período republicano).

Para finalizar, estabelecemos uma análise mais detida do conteúdo do relato de viagem de Macintyre na perspectiva da psicologia ecológica de Tim Ingold buscando no engajamento do missionário um conhecimento pautado por um aprendizado intercultural estabelecido com os Karajá.

\section{Archibald Macintyre: pioneirismo e atuação}

Archie Macintyre foi um missionário escocês que veio para o Brasil em 1907, como agente da South American Evangelical Mission - SAEM (Missão Evangelizadora da América do Sul) Americana, fundada em 1885 na Inglaterra. Uma instituição que na sua origem atuava na Argentina transferindo sua base de atuação para o Brasil por volta de 1905 ao estabelecer bases missionárias nas regiões norte (Maranhão) ${ }^{8}$ e sudeste (São Paulo). Tempos depois a SAEM fundiu com a Evangelical Union of South America - EUSA (União Evangélica Sul

\footnotetext{
${ }^{7}$ INGOLD, Timothy. Da transmissão de representações à educação da atenção. Educação, Porto Alegre, v. 33, n. 1, p. 6-25, jan./abr.2010, p. 21.

${ }^{8}$ Lyndon de Araújo dos Santos demonstra em sua tese de doutorado como diversas agências missionárias inglesas atuaram o estado do Maranhão no início do século XX incluindo as missões entre povos indígenas. Cf. SANTOS, Lyndon de Araújo. As outras faces do sagrado: protestantismo e cultura na Primeira República. (Tese) UNESP-SP, 2004.

${ }^{9}$ As agências que se uniram para constituir a Evangelical Union of South America (EUSA) são: South American Evangelical Mission (SAEM), a que Macintyre estava ligado inicialmente, Regions Beyond Missionary Union e Help for Brazil Mission. Em 1990, a UESA passou a se chamar Latin Link. CAVALCANTE, João Batista. Uma nuvem pequena como a palma da mão. Goiânia, Gráfica Ideal e Editora Ltda, 1914, p. 59.
} 
Americana - UESA), missão responsável pela reivindicação e manutenção de pessoas estrangeiras que levassem a cabo a difusão do protestantismo não apenas no Brasil, mas também em outros países da América Latina como Argentina e Peru.

Ainda na Escócia, Macintyre teria recebido "o seu preparo teológico e chamada para o campo missionário". ${ }^{10}$ Já no país, passou pelo período de um ano em São Paulo no intuito de aprender a língua portuguesa e se adaptar à cultura, provavelmente no Instituto Bíblico fundado por Reginald Young e Frederick Charles Glass no final do século XIX "para treinamento prático de obreiros leigos". ${ }^{11}$

Em 1908, “estabeleceu sua base na cidade de Goiás, [...] e de lá partia para diversas expedições evangelísticas e de colportagem bíblica", ${ }^{12}$ assumindo funções administrativas como presidente da Comissão Executiva da EUSA e superintendente do campo missionário em Goiás. ${ }^{13}$

Era amante de esportes chegando a incentivar (ou até mesmo a iniciar) as primeiras partidas de futebol na Cidade de Goiás ${ }^{14}$. Era também músico e exercia a prática de "medicar" pessoas com medicamentos próprios à base de quinino ${ }^{15}$. Fez várias "viagens de colportagem" pelo país atingindo uma vasta região que ia desde a fronteira com a Bolívia, em Corumbá (MS), até regiões

\footnotetext{
${ }^{10}$ Archibald Macintyre - primeiro missionário residente no estado de Goiás. In: Revista da Escola Dominical - Jovens e Adultos. Departamento de Escolas Dominicais da Igreja Cristã Evangélica no Brasil. Ano 1, n. 1. 1º Trimestre de 1973, p. 8. Disponível no link: http://www.editoracrista.org/40anos/index.php?option=com_fl ippingbook\&view=book\&id=5\&Itemid=3. Acesso: 19/08/2015.

${ }^{11}$ Ibidem, p. 39.

${ }^{12}$ As viagens de colportagem tinham como objetivo e comercializar literaturas religiosas protestantes bíblias, novos testamentos, panfletos. CAVALCANTE, op.cit., p. 58.

${ }^{13}$ Revista... op. cit, p. 9.

${ }^{14}$ DIAS, Cleber. História do esporte no sertão brasileiro: memória, poder e esquecimento, p. 8. Disponível em: https://www.upo.es/revistas/index.php/materiales_historia_deporte/article/viewFile/532/682. Acesso: 14/05/2015.

${ }^{15}$ MACINTYRE, Archie. Descendo o rio Araguaia. Contagem-MG, AME Menor, 2000, p. 98. A quinina é uma substância utilizada no tratamento da malária, retirada da casca da cinchona, uma árvore típica da região ocidental dos Andes, América do Sul, mais especificamente no Equador. Utilizada em suas funções terapêuticas pelos indígenas, a casca da cinchona foi recomendada em 1638 para tratamento da condessa de Cinchon, mulher do vice-rei do Peru, acometida de febre. Depois disso, a casca foi levada para a Espanha, em 1640, pela própria condessa e também por Viga, seu médico oficial. Em 1671 Sir Robert Talbor importou a casca de cinchona para a Inglaterra, ampliando seu conhecimento no meio europeu, sendo utilizada até mesmo por Luiz XIV para tratar-se de uma febre intermitente, fato que o teria levado a pagar valores altos pelo "segredo " curativo oriundo de tal casca. Desde então, o 'segredo' indígena foi gradativamente conhecido ao redor do mundo, porém até 1868 o fornecimento da matéria prima para a fabricação da quinina concentrava-se na América do Sul, situação mudada com o cultivo dessas árvores em regiões da Índia (Ceilão, Himalaia, Ilha de Jamaica). FANSTONE, James. Discussões sobre a quinina: seu uso no tratamento da malária. São Paulo, Imprensa Methodista, s/d, p. 18-19.
} 
mais próximas do estado de Minas Gerais e Goiás, abrangendo a região do entorno da capital goiana no período - cidade de Goiás - por meio de viagens realizadas. Atuou por volta de meio século neste estado quando teria voltado para a Escócia.

A excursão de Macintyre ocorreu em 1920 tendo duração de cinco meses, viajando por via fluvial e por via terrestre. Nesse período ele percorreu núcleos populacionais estabelecidos ao longo rio Araguaia, visitou a ilha do Bananal e passou por cidades como Conceição do Araguaia, Porto Nacional, Natividade e Planaltina. Há indícios de que a escrita de Macintyre ocorrera num período posterior à viagem, quando teria feito anotações em seu caderno, ${ }^{16}$ elemento essencial na composição do relato da viagem constituído por memórias, anotações e informações da época - orais, escritas, iconográficas - oriundas de diversas fontes. ${ }^{17}$

A obra é composta por doze capítulos, num total de cento e três páginas. Podemos dividir a narrativa em duas partes. Metade do livro, ou seja, os seis primeiros capítulos, são destinados ao relato da "descida" do rio Araguaia, do qual nos ocupamos neste artigo. Na outra metade (Capítulos VII - XII) Macintyre descreve o trajeto percorrido após atravessar o rio Tocantins e passar pelas cidades já mencionadas.

No relato é possível vislumbrar o começo e o fim da viagem, descrita de forma linear e evolutiva. A primeira parte engloba dados do contexto histórico dos lugares vivenciados, porém predomina (1) a percepção de Macintyre no tocante à paisagem encantadora do rio Araguaia e de seus habitantes (principalmente os Karajá) e das cidades visitadas e vistas pelo viés da decadência, (2) os aprendizados ocorridos na convivência com os Karajá denotando uma relação intercultural, e, (3) as informações etnográficas dos povos indígenas habitantes da região (Karajá, Xavante, Avá, Javaé, Tapirapé, Kaiapó, Xerente) cujas ponderações sinalizam para a possibilidade de implantação de missões protestantes entre eles.

Todo o relato é permeado por apontamentos subjetivos e, geralmente, valorativos, das percepções experimentadas no decorrer da viagem. Embora contabilize o tempo gasto em cada etapa da viagem na forma de dias passados em cada lugar, não há na escrita referência cronológica no sentido de explicitar dia, mês ou ano em que a viagem se efetivou ou o que o relato foi escrito. A indicação do ano de ocorrência da excursão (1920) se encontra no

\footnotetext{
16 "Este é o nome, escrito em meu caderno com letras grandes e firmes, que está agora diante de mim". MACINTYRE, op. cit., p. 61.

${ }^{17}$ Ibidem, p. 11.
} 
prefácio elaborado pelo filho de Macintyre para a edição portuguesa publicada no Brasil.

Tanto a viagem como o relato em si integram as intenções expansionistas do protestantismo de missão no então estado de Goiás, ainda que o motivo da viagem fosse a demanda por assistência religiosa oriunda de pessoas da região que haviam se convertido ao protestantismo. Já o relato, na qualidade de derivativo da viagem, pretendia a divulgação de lugares desprovidos da intervenção missionária protestante nos ambientes das agências de missões internacionais, com vistas ao levantamento de recursos financeiros e humanos que patrocinassem tais empreendimentos.

A "descida" do Araguaia, propriamente dita, durou cinco semanas na companhia constante dos Karajá, que além de servir de remadores das canoas, também auxiliavam na provisão de alimentos, na orientação do trajeto a percorrer e, principalmente, na mediação das relações com os indígenas encontrados nas diversas aldeias Karajá do rio Araguaia, exercendo a função de intérpretes no contato interétnico.

A narrativa se inicia quando Macintyre se encontrava em Leopoldina (atual Aruanã-GO). "O esforço missionário tem sido mais limitado ao sul de Goiás”, enfatiza logo no prefácio de seu relato. Esta expressão denota uma realidade da expansão do protestantismo no território goiano, concomitante à expansão da linha férrea e à concentração populacional nas regiões sul e sudeste de Goiás nas primeiras décadas do século XX. ${ }^{18}$

Catalão e Ipameri foram as primeiras cidades goianas nas quais repercutiram o impacto da modernização como resultado da implantação da estrada de ferro ao assumir aspectos urbanos modernos e traços culturais distintos oriundos do processo de reurbanização com alargamento de ruas, construção de redes de esgoto e iluminação pública. ${ }^{19}$ Além disso, esses dois municípios e também outros localizados próximos à rodovia foram os que mais receberam imigrantes nacionais e estrangeiros, principalmente os que professavam o protestantismo, como o missionário Frederick Charles Glass que fundaria no ano de 1902 em Catalão, a primeira Igreja Cristã Evangélica no estado. ${ }^{20}$

\footnotetext{
${ }^{18}$ ARAÚJO, Ordália Cristina Gonçalves Araújo. História do protestantismo em Goiás (1890-1940). Dissertação (Mestrado) Programa de Pós-Graduação em História. UFG. Goiânia, 2004.

${ }^{19}$ BORGES, Barsanufo Gomides. $O$ despertar dos dormentes: estudo sobre a estrada de ferro de Goiás e seu papel nas transformações das estruturas regionais (1909-1922). Goiânia: Cegraf, 1990.

${ }^{20}$ CAVALCANTE, op. cit., p. 35.
} 
A região norte de Goiás entre os rios Araguaia e Tocantins explorada por Macintyre entraria o século passado "como a mais desabitada" do Estado, ${ }^{21}$ condição demográfica proporcionada pelo distanciamento geográfico das minas descobertas na região centro-sul (Santa Cruz, Santa Luzia, Meia Ponte, Jaraguá, Vila Boa). Impulsionada pelas bandeiras e mineração ocorridos na primeira metade do século XVIII, a ocupação e o povoamento do território goiano propiciou "a expulsão dos índios, o recuo das vanguardas espanholas e a fixação dos núcleos populacionais estáveis no centro do País". ${ }^{22}$

Outrossim, outros fatores concorreram para a fixação de pessoas em regiões de mineração da Capitania de Goiás tal como Vila Boa, no contexto colonial, sendo eles:

a cuidadosa montagem da administração local, de acordo com as diretrizes da Coroa, e a vivência religiosa e espiritual de seus habitantes, manifesta na organização das associações religiosas e na construção de oratórios, ermidas, capelas e igrejas, consagrados aos seus protetores, ${ }^{23}$

tornando possível a constituição identitária e o enraizamento de homens e mulheres que vivenciavam, via irmandades, uma religiosidade coletiva e popular.

Razões como estas tornaram, ao longo do tempo, a região centro-sul a área mais povoada do estado, sendo que a ocupação de regiões como a do norte goiano "só se processaria com a disseminação da pecuária e da lavoura ao longo do século XIX", ${ }^{44}$ ainda que a atividade pecuarista tenha motivado, no norte, um afluxo populacional desde o final do século XVIII com a frente de expansão pecuarista que, oriunda do Maranhão, adentrava o território goiano pelo Tocantins. ${ }^{25}$

Macintyre faria o trajeto da estrada de ferro em 1908, prosseguindo até estabelecer sua base missionária na então capital do Estado - Cidade de Goiás - para daí viajar por outras regiões próximas ou mais distantes como a do Norte de Goiás, região considerada por viajantes, desde o século XIX,

\footnotetext{
${ }^{21}$ TIBALLI, Eliana Figueiredo Arantes. A expansão do povoamento em Goiás - Século XIX. Dissertação (Mestrado) Instituto de Ciências Humanas e Letras da Universidade Federal de Goiás. Goiânia, 1991, p. 72.

${ }^{22}$ ROCHA, Leandro Mendes. O Estado e os índios: Goiás, 1850-1889. Goiânia: Ed. UFG, 1998, p. 19.

${ }^{23}$ MORAES, Cristina de Cássia Pereira. Do corpo místico de Cristo: irmandades e confraria na Capitania de Goiás 1738-1808. 1 ed. eBook. Jundiaí, SP: Paco Editorial, 2014.

${ }^{24}$ MAGALHÃES, Sônia Maria de. Males do sertão: alimentação, saúde e doenças em Goiás no século XIX. Goiânia: Cânone Editorial, 2014, p. 53-54.

${ }^{25}$ ROCHA, op. cit., p. 23.
} 
“o pior lugar para se viver" em função do grande índice de febres letais, ${ }^{26}$ principalmente nos lugares próximo dos rios, incluindo o Paranã (ao norte) e o Araguaia (ao sul).

Passado um período, já em 1920, o missionário consideraria Palma - pequena cidade localizada entre os rios Palma e Paranã - uma "das piores zonas da terrível febre do Estado de Goiás", ${ }^{27}$ levando-o a compor a sua bagagem com itens de literatura religiosa e do famoso sulfato de quinina utilizado no século XIX para aliviar as febres. Porém, visto que nem todos podiam comprá$-10,{ }^{28}$ dispunha do mesmo na forma de doação ou na forma de cobrança de uma pequena taxa para o seu uso quando a procura era demasiada, visto o elevado número de doentes necessitados dessa substância. ${ }^{29}$ Em muitos locais as pessoas o consideravam "Doutor", requerendo sua atenção por meio do atendimento dispensado aos doentes ${ }^{30}$ conforme relata durante sua estadia em Cavalcante:

Durante a estadia ali estive bem ocupado medicando as pessoas com quinino, o que felizmente tinha um bom suprimento e, entre aqueles doentes mediquei dois homens, que como nós, estavam de passagem pela cidade. Não existe um só médico num raio de 400 quilômetros e, todos estavam acometidos de malária. Pediram-me para visitar uma mulher que estava morrendo e vi sua condição. Era inacreditável. ${ }^{31}$

Por este trecho, dentre outros, reiteramos que Macintyre era um médico prático, um ofício exercido também por fazendeiros em virtude da rara assistência médica em lugares mais distantes da capital e das regiões litorâneas como o norte de Goiás no início do século XX.

Além da localização interiorana, outro agravante para esta carência médica desde o século XIX seria os parcos recursos financeiros destinados a tal fim, fazendo com que os goianos se valessem de produtos de natureza vegetal (plantas, raízes medicinais, cascas, folhas, frutos, sementes, óleos e resinas), animal (couro, gorduras, excrementos), mineral e de origem química presente nos compostos homeopáticos para tratar suas moléstias. Todavia, quando a doença mostrava-se resistente aos medicamentos caseiros, buscava-se a

\footnotetext{
${ }^{26}$ MAGALHÃES, op. cit., p. 95.

${ }^{27}$ MACINTYRE, op. cit., p. 96.

${ }^{28}$ MAGALHÃES, Sônia Maria de. op. cit., p. 104.

${ }^{29}$ MACINTYRE, op. cit., p. 63.

${ }^{30}$ Ibidem, p. 78.

${ }^{31}$ Ibidem, p. 98.
} 
ajuda "especializada" de indivíduos que se achavam habilitados, portadores ou detentores de saberes curativos. ${ }^{32}$

Como médico prático, ele atendia pessoas com moléstias distintas da febre, como, por exemplo, o jovem que tinha uma das mãos inflamada e infeccionada. Atendia ainda não apenas nos lugares pelos quais passava, mas também na sede da Missão na Cidade de Goiás, pois pessoas vinham até ele para serem tratadas. ${ }^{33}$

O relato de Macintyre é referenciado na Bibliografia crítica da etnologia Brasileira que retrata a versão inglesa publicado em Londres em 1923. O antropólogo teuto-brasileiro Hebert Baldus, autor da Bibliografia, apresenta um rápido comentário desta obra indicando que a mesma contém "ligeiras referências aos Karajá, Javahé, Canoeiros, Chavante do rio das Mortes, Cherente, Tapirapé e Kaiapó do norte", um mapa e imagens ao longo do texto. ${ }^{34}$

A inclusão desse relato - bem como de outros missionários protestantes - na bibliografia significa que esta narrativa era vista como fonte etnográfica para os estudos relacionados aos indígenas do Brasil Central. Apesar de portar uma máquina fotográfica, Macintyre deixa claro que algumas das fotografias expostas ao longo do relato eram do Coronel Eugênio Rodrigues Jardim (18581926), presidente do estado de Goiás no período de 1921-1923.

Dada a referência de Baldus, percebemos a reverberação do relato de viagem de Macintyre não apenas entre as agências missionárias protestantes destinadas à América Latina. Os limites dos ambientes religiosos foram extrapolados quando o relato se tornou em uma das referências aos estudos etnográficos dos povos indígenas da região central do Brasil, algo que era efetivado com anuência do Sistema de Proteção ao Índio (SPI) fundado em 1910.

Originalmente publicada em língua inglesa com o título Down the Araguaya: travels in the heart of Brazil e prefaciada por J. Stuart Holden, o relato foi replicado em nosso país no ano de 2000. Na versão traduzida para a língua portuguesa, coube a Tom E. Macintyre, filho de Archibald Macintyre, a tarefa de prefaciar a obra. Num objetivo aparente de publicizar de modo mais amplo - a partir da tradução para o português - as situações, experiências e aprendizados vividos por Macintyre, seu relato torna-se um componente

\footnotetext{
${ }^{32} \mathrm{~A}$ medicina prática tinha sua base nos manuais de medicina - A medicina doméstica (Buchanan), Dicionário de medicina doméstica e popular (Teodoro Langaard) e Dicionário de Medicina Popular (Chernoviz) - que desde o século XIX até o início do XX divulgavam princípios médicos auxiliando as pessoas desses lugares mais distantes a lidar melhor com as doenças a que eram acometidas. MAGALHÃES, op. cit., p. 165; 170-171.

${ }^{33}$ Ibidem, p. 58.

${ }^{34}$ BALDUS, Herbert. Bibliografia crítica da etnologia brasileira. São Paulo, 1954, V. 1. Comissão do IV Centenário da Cidade de São Paulo, Serviço de Comemorações Culturais, p. 417.
} 
importante para o processo de enquadramento da memória ${ }^{35}$ constitutiva da história da expansão protestante no estado de Goiás pelos missionários que fundariam a Igreja Cristã Evangélica do Brasil (ICEB).

\section{O Vale do Araguaia e as intenções civilizadoras}

O rio Araguaia localiza-se na região central do Brasil, correspondendo aos atuais estados de Goiás, Tocantins, Mato Grosso e Pará sendo, desde o início da colonização europeia, séculos XVII e XVIII, local de passagem de inúmeras expedições, constituídas basicamente por duas frentes de contato: as das capitanias do Sul, especialmente de São Vicente (São Paulo) e a da Amazônia Portuguesa. Tais frentes vagavam por estas regiões em busca de ouro ou do apresamento indígena. Ocasiões em que os bandeirantes deparavam, inevitavelmente, com os Karajá e outros povos indígenas.

Desde o final do século XVI já se tem as primeiras informações de que os Karajá habitavam as margens desse rio. ${ }^{36}$ Provavelmente, num período anterior a 1500, os Karajá tenham-se movimentado do eixo mais baixo do rio (norte), próximo à sua foz no Tocantins, em direção ao seu alto curso (sul), fato que teria provocado a dispersão desse povo em vários grupos que se fixaram em distintas regiões ao longo do Araguaia, incluindo a Ilha do Bananal (médio curso do rio). Atualmente, o maior índice populacional dos Karajá encontra-se localizado nesta ilha no Parque Indígena do Araguaia. ${ }^{37}$

Macintyre realizou praticamente todo o percurso da primeira etapa de sua viagem, o trecho que inclui a navegação no rio Araguaia, na companhia de indígenas Karajá que ora lhes servia de guia, conduzindo-o nas embarcações como remadores da ubá (embarcação indígena) e provendo recursos alimentícios oriundos de caças e pescas, ora lhes servia de intérprete nas inúmeras aldeias que visitou durante a excursão.

A função de intérprete assumida pelo indígena é algo recorrente nas fontes históricas que tratam dos contatos estabelecidos entre colonizadores e indígenas na história dos "descimentos, bandeiras, aldeamentos, presídios e escolas voltados aos indígenas” tornando-se, em alguns momentos,

\footnotetext{
${ }^{35}$ POLLAK, M. Memória e identidade social. Estudos Históricos, Rio de Janeiro, vol. 5, n. 10, 1992, p. $200-212$, p. 7. ${ }^{36}$ Ibidem, p. 14-23.

${ }^{37}$ TORAL, op. cit., p. 14; SILVA, Maria do Socorro Pimentel da. Impactos da educação na vitalidade do patrimônio epistêmico Iny. Goiânia: Kelps, 2015, p. 14.
} 
responsáveis pelo sucesso das expedições, mas em outros, seus desarticuladores e até mesmo sabotadores. ${ }^{38}$

A utilização do indígena como interlocutor com o não indígena assumiu caráter de política do governo imperial com a instalação de colégios nos aldeamentos ou presídios ${ }^{39}$ para formação destes intérpretes que deveriam mediar as intenções de conquista, assimilação e incorporação do indígena à sociedade nacional. Neste contexto, em 1870 é fundado o Colégio de Línguas Princesa Imperial Dona Isabel (1870 - 1889) em Leopoldina (atual Aruanã) pelo general José Vieira Couto de Magalhães (1837-1898), ${ }^{40}$ no intuito de "impor uma nova educação às crianças indígenas, preservando, ao mesmo tempo, as línguas de suas tribos para que servissem de mediadores quando reintroduzidos em suas tribos de origem". ${ }^{41}$

De modo mais amplo, a criação deste Colégio inseria-se nos intentos "civilizacionais" dos líderes políticos goianos, fosse pelo desenvolvimento da navegação fluvial dos rios Araguaia e Tocantins fosse pela ocupação territorial para formação de fazendas pecuaristas. Em tal projeto, os indígenas, seriam incorporados não apenas como "intérpretes nas conversações que se fizessem necessárias" - com os missionários dominicanos e capuchinhos durante o processo de catequização e com os negociantes em suas transações comerciais - mas, sobretudo, como trabalhadores úteis, porém, marginalizados e inferiorizados, nos processos de desenvolvimento e de ocupação territorial da então Província de Goiás.

A existência do Colégio não foi mencionada por Macintyre quando passou por Leopoldina. o que o missionário registrou reflete a noção de

\footnotetext{
${ }^{38}$ DIAS, Thiago Cancellier. Contatos e desacatos: os línguas na fronteira entre sociedade colonizadora e indígenas (1740 a 1889) - Goiás. Espaço Ameríndio, Porto Alegre, v. 7, n. 2, p. 205-226, jul./dez.2013.

${ }^{39}$ Como extensão da política colonizadora ibérica nas colônias africanas e latino-americanas, os presídios, no Brasil, representavam a ação colonizadora. No norte do então estado de Goiás, a construção destes destacamentos militares surgiu da necessidade de implementar a navegação do rio Araguaia e o povoamento da região, política oficial implementada principalmente a partir de 1850, ainda que outros presídios já tivessem antes sido construídos (São João das Duas Barras - 1802 e Santa Maria do Araguaia - 1812). Inicialmente estas pequenas colônias eram construídas com recursos do governo para fixar moradores na região. Porém, com o passar do tempo, as mesmas deveriam se estruturar para se autossustentar. TIBALLI, op. cit., p. 80-86.

${ }^{40}$ Político, militar, escritor e folclorista brasileiro que ocupou cargos de Presidente de Província de Goiás (1863-1864), Pará (1864-1866), Mato Grosso (1867-1868), período em que atuou na Guerra do Paraguai e, por fim, São Paulo (1888). Conhecido por empreender a primeira exploração do rio Araguaia e inaugurar em 1868 a navegação a vapor neste mesmo rio. ARAÚJO, Patricia Simone. Vasculhando a vida alheia: o diário íntimo de José Vieira Couto de Magalhães (1880-1887). Dissertação (Mestrado). Programa de Pós-Graduação em História, Universidade Federal de Goiás, 2012, p. 13.

${ }^{41}$ MARIN, Joel Orlando Bevilaqua Marin. A formação de trabalhadores brasileiros: a experiência do Colégio Isabel. História Unisinos. 13(2):154-167, Maio/Agosto, 2009, p. 155-156.
} 
decadência que ficou impregnada na historiografia goiana a partir dos relatos produzidos por viajantes que viajaram por Goiás nas primeiras décadas do Oitocentos e também nos relatos dos governadores de província. No período de existência do referido Colégio, Leopoldina ${ }^{42}$ era uma importante vila portuária. ${ }^{43}$ Em suas palavras, o vilarejo

Tinha umas duas dúzias de casebres, na sua maioria de frente para o rio, com evidentes sinais da antiga prosperidade e da decadência atual. Os cascos enferrujados de três pequenos barcos à vapor, estavam atolados na areia à beira do rio, enquanto os restos da oficina para consertos podem ser vistos ao algo. Estes barcos fizeram um bom serviço antes do Brasil tornar-se uma República, e são testemunhas do magnífico fracasso de Couto Magalhães - cujo nome será sempre associado com este grande rio - e foram também um desafio ao empreendimento brasileiro. ${ }^{44}$

A narrativa de Macintyre sinaliza para uma ideia que permeou as análises históricas de Goiás claramente visível nos trabalhos produzidos por historiadores importantes da historiografia regional de Goiás como Luis Palacín (1979), Maria Augusta Sant’Anna Moraes (1978) e Dalísia Doles (1973). De modo geral, o enfoque destes trabalhos está na "ênfase aos aspectos da decadência e da precariedade da vida goiana, à estagnação econômica caracterizada por arraiais e vilas abandonados e à indefinição em termos econômicos". ${ }^{45}$

Uma ideia que atravessou todo o Império, adentrando a Primeira República, conforme observamos no relato do missionário protestante. Todavia, a decadência como categoria de análise da História de Goiás até 1930 passou por um processo revisionista no final dos anos 1970 encampado por historiadores como Paulo Bertran, Eurípedes Funes, Tarcísio Botelho e Nasr Chaul, os quais "apontaram novos caminhos para a interpretação da história social e econômica regional ao longo do século XIX”, bem como a "urgência da revisão" das obras historiográficas anteriormente produzidas sobre o contexto goiano no século XIX tendo por base "as observações feitas pelos viajantes estrangeiros".

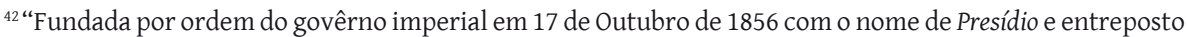
do comércio de Goiás com o do Para. Foi o seu primeiro comandante o sargento de linha Cyriaco José de Azevedo, que ali chegou até o posto de Capitão do Exercito" (Nota de Otaviano Esselin, tradutor da obra Entre os índios do Araguaia de Estevão M. Gallais (GALLAIS, Estevão M. Entre os índios do Araguaia. Livraria Progresso Editora, Bahia, Salvador, 1954, p. 43).

${ }^{43}$ MARIN, op.cit., p. 158.

${ }^{44}$ MACINTYRE, op. cit., p. 13, grifos nosso.

${ }^{45}$ MAGALHÃES, op. cit., p. 57.
} 
Esta revisão historiográfica resultou na possibilidade mais ampla de inclusão de novos objetos e novas abordagens deste período na historiografia regional produzindo profícuos estudos na área da alimentação, ${ }^{46}$ saúde, ${ }^{47}$ comportamentos ${ }^{48}$ irmandades e confrarias, ${ }^{49}$ instituições,${ }^{50}$ dentre outros.

Observamos que o olhar de Macintyre estava enquadrado num molde cujas raízes remontavam aos relatos dos viajantes - oriundos praticamente do mesmo lugar de enunciação - que passaram por Goiás no início do século XIX. Era a perspectiva de uma realidade regional legitimada por lentes europeias que, dado o contexto ideológico da época, projetava sua imagem "civilizada", para um mundo considerado "decadente", "atrasado" e, principalmente "selvagem".

Analisar a obra de Macintyre, portanto, para além de sua percepção da cidade de Leopoldina, brevemente descrita na narrativa, possibilita perceber as minúcias de sua narrativa quanto à percepção do indígena ao longo do rio Araguaia ao trazer dados sobre diversos povos indígenas: "carajá”, "chavantes", "canoeiros", "javaés", “caiapós” e "cherentes". "Vale a pena estudar o índio”, ele afirma.

Como agente de um projeto missionário de atuação na América Latina, ${ }^{51}$ observamos que sua viagem resulta dos desdobramentos das discussões do Congresso do Panamá ocorrido em 1916, considerando o Brasil como campo de missões protestantes, incluindo entre as pessoas a serem catequizadas, católicos e indígenas.

Após 1916 foi criado um programa de missão aos índios com vistas a "levantar informações e dados a respeito do problema indígena, de maneira a criar uma biblioteca e um arquivo especializado", para subsidiar o estudo dos diversos grupos indígenas do país. Este programa se constituiu a partir de uma "estreita colaboração com agentes do Serviço de Proteção ao Índio

\footnotetext{
${ }^{46}$ MAGALHÃES, op. cit.; MEIRELES, Marilúcia Melo. Os "bobos" em Goiás: enigmas e silêncios. 1.ed. Goiânia: Editora UFG, 2014.

${ }^{47}$ SILVA, Leicy Francisca da. Eternos Órfãos da Saúde: medicina, política e construção da lepra em Goiás (1830 - 1962). Tese (Doutorado) - Universidade Federal de Goiás, Faculdade de História, 2013.

${ }^{48}$ RABELO, Danilo. A normalização dos comportamentos na Cidade de Goiás, 1822-1889. Goiânia: Universidade Federal de Goiás/Programa de Pós-Graduação em História/FUNAPE, 2010.

${ }^{49}$ MORAES, op. cit..

${ }^{50}$ SOUZA, Rildo Bento de. Pobreza, doenças e caridade em Goiás: uma análise do Asilo São Vicente de Paulo (1909-1935). Jundiaí, Paco Editorial, 2014.

${ }^{51}$ GONÇALVES, Carlos Barros. Até aos confins da terra: o movimento ecumênico protestante no Brasil e a evangelização dos povos indígenas. Dourados: Ed. UFGD, 2011.
} 
na sistematização de dados e na reunião de livros e documentos relacionados aos diversos grupos étnicos..$^{52}$

Todavia, a missão que Macintyre representava - EUSA - ainda não tinha estabelecido um trabalho de evangelização indígena na região, pois assim se manifestou ao começar os preparativos de retorno de sua viagem, na cidade de Conceição do Araguaia:

Já está mais do que adiantada a hora de começar o evangelismo desse povo esquecido. Ficamos contentes em saber que vários olhos estão se tornando para essa direção e cobiçam essa honra. Uma fazenda na Ilha do Bananal seria um bom começo e logo cobriria os custos de manutenção..$^{53}$

Embora não houvesse um trabalho efetivo de protestantização na região do Vale do Araguaia, os contatos promovidos pelos agentes dessas missões já vinham ocorrendo desde $1906,{ }^{54}$ culminando, nas décadas seguintes, na consolidação de missões protestantes em comunidades Karajá incluindo as aldeias Macaúba (Evangelical Union of South American, 1906-1935) e Fontoura (Missão Brasil Central, 1935-1947). Prevalece, entretanto, no meio acadêmico, a menção aos trabalhos desenvolvidos pela Igreja Adventista do Sétimo Dia entre os Karajá, ${ }^{55}$ uma questão instigante, pois a missão protestante efetivada na Ilha do Bananal pelos missionários britânicos foi responsável por "um posto médico, uma escola e um auxílio aos leprosos que eram ali amparados". ${ }^{56}$

Tais informações referenciam inicialmente a assistência médica oferecida por Rettie Buchan desde 1925 ano em que foi construído o "primeiro leprosário filantrópico em Goiás” - o leprosário Macaúbas - tendo à frente Josiah Wilding ${ }^{57}$ - que casaria com Rettie em 1932. Quando da morte do primeiro (vítima de malária) e transferência da médica-missionária para trabalhar na cidade de Anápolis, Macintyre assumiu a direção do trabalho expandindo suas ações estratégicas com a construção de um hospital e de uma farmácia. Sobre este contexto, Tom Macintyre, filho do missionário, expressou:

\footnotetext{
${ }^{52}$ GONÇALVES, op. cit., p. 131-132, grifo no original.

${ }^{53}$ MACINTYRE, op. cit., p. 72.

${ }^{54}$ TORAL, op. cit., p. 46.

${ }^{55}$ BUENO, Marielys Siqueira. Macaúba: uma aldeia Karajá em contato com a civilização. Universidade Federal de Goiás (Dissertação de Mestrado), Goiânia, 1975; TORAL, op. cit.; PRESTES FILHO, Ubirajara de Farias. $O$ indígena e a mensagem do segundo advento: missionários adventistas e povos indígenas na primeira metade do século XX. Tese (Doutorado em História Social) - FFLCH, Universidade de São Paulo, 2006; PORTO, José Justino. Missão adventista entre os karajá de Santa Izabel do Morro: 1980 a 2000. 103 f. Dissertação (mestrado) - Pontifícia Universidade Católica de Goiás, Departamento de Filosofia e Teologia, 2009.

${ }^{56}$ MACINTYRE, op. cit., p. 9.

${ }^{57}$ SILVA, op. cit., p. 172.
} 
Após a morte de seu marido, Josias Wilding, a Dra Rettie continuou liderando o trabalho médico ali, só subindo para a civilização para ter seu filho, hoje Dr. Josias Wilding, e voltando para o árduo trabalho na ilha. Quando finalmente a Dra. Rettie deixou a Ilha do Bananal para trabalhar no Hospital Evangélico Goiano em Anápolis, o posto médico foi fechado. Voltando de férias da Escócia e ouvindo a triste situação dos leprosos na Ilha que esperavam transferência para o leprosário em Goiânia, meu pai desceu o rio para ver o que poderia fazer para ajuda-los. A primeira necessidade era de alimento, e logo saiu em busca de mantimentos para aquela pobre gente..$^{58}$

É provável que "o estabelecimento tenha subsistido por um período posterior à inauguração da Colônia Santa Marta em Goiânia (1943), e que tenha sido o Pará o destino de alguns internos, devido à proximidade espacial com aquele estado, outra parte dessa população foi enviada à Goiânia". ${ }^{59}$

\section{A relação com os indígenas: diálogo intercultural}

Analisar a obra de Macintyre nos leva a considerá-lo como um "observador" pronto a narrar o que se apresenta diante de si na intenção de "conhecer" a região, divulgar e comercializar literaturas religiosas, realizar reuniões protestantes e, por fim, viabilizar o trabalho missionário entre os indígenas e cidades do norte do estado de Goiás. Além disso, o missionário - como sujeito oriundo de outra cultura - ao buscar o conhecimento da região do rio Araguaia e das cidades do então norte de Goiás no início do século XX e seus respectivos habitantes, o faz partindo de percepções (olhar, ouvir ou sentir) geradas no movimento de influência mútua entre observador e observado. ${ }^{60}$

Este movimento transparece na escrita de Macintyre em diversos momentos. Dentre eles, o da preparação da viagem em si no que se refere à alimentação ao longo de cinco meses. A provisão para esta longa viagem era apenas duas pequenas latas de leite condensado e duas de aveia (Quaker Oats), pois, de acordo com seus escritos, viveria do "fruto da terra e do rio", algo que foi possível pela presença do guia e remadores indígenas, no trecho fluvial percorrido. Os mesmos pescavam peixes (pintado, piranha, pacu, pirarucu),

\footnotetext{
${ }^{58}$ MACINTYRE, op. cit., p. 9.

${ }^{59}$ SILVA, op. cit., p. 175.

${ }^{60} \mathrm{O}$ distanciamento entre observador e observado tem seus fundamentos no ideal científico ilustrado, no qual o primeiro localiza-se num ponto zero, ou seja, numa plataforma neutra e imparcial de observação da realidade sociocultural a partir da qual o observador nomeia o mundo observado. Este ponto zero permite não apenas a nomeação do observado, mas também a legitimação do discurso do observador como válido. CASTRO-GÓMEZ, Santiago. La hybris del punto cero: ciencia, raza e ilustración en la Nueva Granada (17501816). 1a ed. Bogotá: Editorial Pontificia Universidad Javeriana, 2005, p. 14, 24-25.
} 
caçavam animais (veado, porco do mato, onça, tartaruga, abutre, jacaré, jaburu, ariranha) e coletavam frutos do ambiente (mangaba, banana, inhame).

Outro momento ocorre ao referenciar um convite para jantar feito a ele por parte de um indígena Karajá. Ao conhecer a aldeia, sob direção do indígena, o missionário afirma: "Muita coisa me interessava e da mesma forma eu era objeto do interesse deles". ${ }^{61}$ Em outro trecho afirma que um grupo de mulheres e crianças indígenas teciam comentários a seu respeito na língua nativa, que era incompreensível para o mesmo. ${ }^{62}$

Seguindo a psicologia ecológica, o conhecimento ocorre num campo de relações, onde se processa a cópia, ou seja, "seguir o que as outras pessoas fazem", buscando uma sintonia fina com as mesmas no sentido de ir na mesma direção. Este "ir na mesma direção" significa incorporar o conhecimento dessas pessoas e expressá-los na prática em "ações corporificadas [enactions] no mundo". ${ }^{63}$ Encontramos na narrativa do missionário esse processo de copiar, numa expressão do desenvolvimento da afinação do processo perceptivo por meio do olhar, ver e sentir manifesto em atitudes de "aceitação" frente à cultura indígena:

Sem qualquer cerimônia um grande pedaço de peixe cozido (pirarucu), numa bandeja de madeira, foi colocado no chão da maloca. O pequeno grupo sentado com as pernas cruzadas ao redor do peixe entrou em ação com muito entusiasmo, tirando enormes pedaços do peixe com os dedos, e eu, naturalmente, como hóspede de honra, os segui. Mas, que cena! Costumava ler à respeito nos livros, mas aqui a coisa era autêntica. [...] Em seguida apareceram grandes bolos brancos e finos, dos quais tirávamos pedaços à vontade.

[...]

Realmente a vida era simples, nada de garfos, facas, pratos, mesas e cadeiras. Nada de formalidades ou ostentação, no entanto, com muita naturalidade e ausência de vulgaridade que fez com que anelássemos... mas para que serve desejar, quando se tem o infortúnio de não ter nascido Carajá? ${ }^{64}$

Conhecer, então, "é imanente à vida e consciência do conhecedor, pois desabrocha dentro do campo de prática - a taskscape - estabelecido através de sua presença enquanto ser-no mundo. A cognição, neste sentido, é um processo em tempo real". ${ }^{65}$ Para os indígenas, sobretudo os povos Iny (Karaja

\footnotetext{
${ }^{61}$ MACINTYRE, op. cit., p. 39.

${ }^{62}$ Ibidem, p. 44.

${ }^{63}$ INGOLD, Timothy. Da transmissão de representações à educação da atenção. Educação. Porto Alegre, v. 33, n. 1, p. 6-25, jan./abr.2010.

${ }^{64}$ MACINTYRE, op. cit., p. 41-42, grifo do autor.

${ }^{65}$ INGOLD, op. cit., p. 21.
} 
e Javaé), esta afinação do processo perceptivo é algo natural e mais que isto, desejável. Em sua mitologia as pessoas são constituídas por meio da troca de fluídos (humanos ou não), numa perspectiva que casa-se perfeitamente com o enfoque enactivo. ${ }^{66}$

A convivência de Macintyre com os Karajá o levaria ao conhecimento de aspectos da vida deste povo, seguindo comportamentos inerentes aos indígenas. Indícios como estes evidenciam novamente que a distinção entre observador e observado deixa de existir. Principalmente quando Macintyre se expressou em relação à sua "educação imperfeita" ao não ter habilidade para encontrar os ovos de tartaruga nas praias do rio Araguaia:

Por mais que experimentasse, nunca conseguia acertar o ninho da tartaruga, fato que os Carajás achavam muito divertido (engraçado), e se perguntavam que tipo de educação eu tivera na minha mocidade, pois não conseguia descobrir o segredo da Dona Tartaruga. Depois de apreciar este entretenimento às minhas custas, eles vinham em meu auxílio, apontando o lugar exato com o dedão do pé. ${ }^{67}$

A suposta superioridade da educação do missionário era questionada pelos Karajá por não compreenderem o motivo pelo qual Macintyre não encontrava os ovos de tartaruga, visto tratar-se de um conhecimento vinculado à percepção do ambiente. Se na condição de "observador" a função do missionário seria descrever, nomear e classificar o lugar por onde passava e as pessoas que encontrava, por outro lado, o indígena também elaborava suas percepções e considerações em relação a ele, que alvo de observação também. Daí a eliminação do binômio observador e observado visto que nem o missionário nem os Karajá situavam-se num lugar privilegiado de observação isento de qualquer interferência subjetiva.

Não obstante as trocas e os diálogos interculturais manifestos nas enações entre Macintyre e indígenas, é visível no texto atitudes e olhares eurocentrados do missionário para com o ambiente goiano, fato parcialmente demonstrado acima.

Estas práticas se manifestam por meio de parâmetros comparativos que envolvem aspectos da região goiana em relação ao seu lugar de origem como comparar a área geográfica da Escócia com a do estado de Goiás, que sob sua avaliação seria oito vezes maior que o país europeu, ou comparar o rio Araguaia - na largura que tem na altura da cidade de Aruanã - ao rio Tâmisa

\footnotetext{
${ }^{6}$ RODRIGUES, Patrícia de Mendonça. O meio como o lugar da história. CAMPOS - Revista de Antropologia Social, v. 8, n. 1, 2010, p. 33-43.

${ }^{67}$ MACINTYRE, op. cit., p. 26.
} 
(Inglaterra). Porém enaltece o primeiro e sinaliza sua satisfação diante da paisagem que vislumbra, levando-o a admitir que "Este não era um conto de fadas, aqui estavam os Carajás de verdade... e nós no meio de tudo". ${ }^{68}$

Narrações como estas permitem enquadrar o texto em questão sob o molde diversificado do relato de viagem, visto que uma de suas características é o fato de os mesmos recorrentemente lidarem "de forma sistemática com as noções do aqui e do acolá", operando "com noções variadas de mudanças e transições" "69 em espaços sociais de encontros entre culturas distintas nos quais estas "se encontram, se chocam, se entrelaçam" ", estabelecendo contatos interculturais.

A comparação se estende para as sensações que Macintyre experimentou ao navegar pelo rio Araguaia. Sensações de contemplação, estímulo e alívio das tensões inerentes às sociedades industriais, possíveis por se tratar de um ambiente que se assemelha a um paraíso encantado ao referendar um mundo natural, constituído por uma natureza exuberante, intocada e habitada por sujeitos que vivem uma "vida natural".

Como é lindo o rio ao amanhecer! Como é estimulante o ar no meio do rio! Como estas águas são plácidas! Que cura maravilhosa para as pessoas de um mundo tão distante, tensas devido ao corre-corre e sempre com pressa em tudo. Muitos viriam se soubessem desse paraíso desconhecido, mas nos sentimos egoisticamente felizes por não saberem, pois o encanto seria desfeito para sempre. Encontrar um barco cheio de turistas com seus guias, binóculos, câmeras, etc., seria uma tragédia, e nos sentimos felizes pelo índio que ainda rema a sua ubá e vive uma vida natural nestas águas como faziam antes do descobrimento da América do Sul. ${ }^{71}$

O olhar eurocentrado de Macintyre é visível também pelos critérios hierarquizadores - "selvagem", "semisselvagem", "selvagens encantadores", "gente boa", "bravos" e "temíveis" - que lançou mão para caracterizar os indígenas em relação à "civilizada" cultura não indígena.

O termo "selvagem" foi recorrentemente utilizado no relato em referência aos indígenas conforme exemplificação do trecho a seguir: "Exatamente uma semana depois de deixar São José, deparamos com uma grande aldeia de

\footnotetext{
${ }^{68}$ Ibidem, p. 16.

${ }^{69}$ Outros itens que caracterizam um relato de viagem são: a pressuposição de um leitor, a relevância do período da escrita (logo após a viagem ou muito tempo depois), o fator de influência para inspirar e mobilizar outras viagens e, finalmente, o problema da "veracidade" dos conteúdos elaborados. JUNQUEIRA, M. A; FRANCO, S. M. (Orgs). Op. cit., p. 48-51.

${ }^{70}$ PRATT, Mary Louise. Os olhos do império: relatos de viagem e transculturação. Bauru-SP: EDUSC, 1999, p. 27.

${ }^{71}$ MACINTYRE, op. cit., p. 18-19.
} 
índios em uma grande praia, e logo em seguida, cinco grandes ubás repletas de selvagem nus e pintados para a guerra vieram nos dar boas vindas"..$^{72} \mathrm{~A}$ medida que os indígenas eram integrados na sociedade envolvente, o termo "selvagem" surge, na escrita, acompanhado de adjetivos qualificadores do tipo de relação que o missionário e os indígenas mantinham entre si. As expressões "selvagens encantadores" e "gente boa" apontam para os Karajá, em virtude da proximidade destes para com a cultura branca e, sobretudo, pelo fato de que eles foram extremamente úteis na excursão de Macintyre pelo rio Araguaia.

Os termos "bravos" e "temíveis" indicam os Ava-canoeiro e os Xavante, respectivamente. São adjetivações complementadas, na narrativa, por explicações que afirmam que os dois últimos povos ainda não teriam sido visitados pelo homem "civilizador", habitando terras distantes e inexploradas, como se o contato fosse uma via para extinguir o caráter "selvagem" de tais sociedades. Já a expressão "semisselvagem" referendava indígenas que haviam convivido com não indígenas e passado por um processo de assimilação de aspectos da sociedade envolvente, como o aprendizado da Língua Portuguesa e das práticas cristãs.

Posturas como a de Macintyre de hierarquizar sociedades como as etnias indígenas é discutida de forma crítica pelo coletivo Modernidade/ Colonialidade/Decolonialidade, ao ponderar que

os europeus geraram uma nova perspectiva temporal da história e re-situaram os povos colonizados, bem como a suas respectivas histórias e culturas, no passado de uma trajetória histórica cuja culminação era a Europa (Mignolo, 1995; Blaut, 1993; Lander, 1997). Porém, notavelmente, não numa mesma linha de continuidade com os europeus, mas em outra categoria naturalmente diferente. Os povos colonizados eram raças inferiores e - portanto - anteriores aos europeus. ${ }^{73}$

Nesse sentido, "raça" e "cultura", tornam-se em dispositivos taxonômicos geradores de identidades opostas a partir do que Castro-Gómez ${ }^{74}$ denominou de "invenção do outro", termo que sinaliza tanto a maneira como um grupo de pessoas projeta a sua própria representação a outro grupo social, como o dispositivo de saber/poder que funciona como ponto de partida para construir estas mesmas representações. Assim, tal dispositivo estaria

\footnotetext{
${ }^{72}$ Ibidem, p. 37.

${ }^{73}$ QUIJANO, Anibal. Colonialidade do poder, eurocentrismo e América Latina. In: LANDER, Edgardo (Org). A colonialidade do saber: eurocentrismo e ciências sociais. Perspectivas latino-americanas. Colección Sur Sur, CLACSO, Ciudad Autónoma de Buenos Aires, Argentina, 2005. p. 111.

${ }^{74}$ QUIJANO, op.cit., p. 81.
} 
embasado nas argumentações elaboradas pelos teóricos sociais europeus dos séculos XVII e XVIII (Hobbes, Bossuet, Turgot, Condorcet), para quem os "seres humanos" passariam por "estágios" de aperfeiçoamento, deixando gradativamente a ignorância até assumir "maioridade" nos moldes das sociedades modernas europeias. ${ }^{75}$ Desta forma,

O referencial empírico utilizado por este modelo heurístico para definir qual é o primeiro "estágio", o mais baixo na escala de desenvolvimento humano, é o das sociedades indígenas americanas tal como estas eram descritas por viajantes, cronistas e navegantes europeus. A característica deste primeiro estágio é a selvageria, a barbárie, a ausência completa de arte, ciência e escrita. "No princípio, tudo era América", ou seja, tudo era superstição, primitivismo, luta de todos contra todos, "estado de natureza". o último estágio do progresso humano, aquele alcançado pelas sociedades européias, é construído, por sua vez, como "o outro" absoluto do primeiro e à sua contraluz. Ali reina a civilidade, o Estado de direito, o cultivo da ciência e das artes. O homem chegou ali a um estado de "ilustração" em que, no dizer de Kant, pode autolegislar-se e fazer uso autônomo de sua razão. A Europa demarcou o caminho civilizatório pelo qual deverão transitar todas as nações do planeta. $^{76}$

Este dispositivo ideológico manifesta-se nas lentes europeias de Macintyre expressas pela utilização, na sua narrativa, dos termos já mencionados como etapas processuais de um percurso linear pelo qual deveria passar as sociedades indígenas encontradas por ele, por meio do "progresso" levado a efeito pela sociedade nacional, ao incorporar o indígena como trabalhador na cultura "civilizada". Intento que já vinha ocorrendo desde 1870 com a criação do Colégio Isabel no contexto da ocupação territorial da região norte da Província de Goiás com o objetivo claro de constituir fazendas de criação de gado.

Aliado à ocupação espacial outro processo concomitante seria a expropriação dos indígenas de suas terras para se tornarem mão de obra nos trabalhos das fazendas, como vaqueiros, e, além disso, "transformá-los em bons marinheiros, mecânicos, carpinteiros e ferreiros" durante o período de navegação fluvial dos rios Araguaia e Tocantins, momento em que exerciam a função de fornecer "lenha para mover os barcos a vapor e alimentos aos tripulantes, recebendo em troca machados, facões, anzóis, roupas e outros objetos". ${ }^{77}$ Enfim,

\footnotetext{
${ }^{75}$ CASTRO-GÓMEZ, op. cit., p. 83.

${ }^{76}$ Ibidem.

${ }^{77}$ MARIN, p. 155, 158, 164
} 
Desejava-se transformar os índios, desde crianças, em instrumentos da produção econômica, por meio de uma educação que inculcasse uma outra racionalidade e uma outra religião, com a nítida intenção de ressocializá-los e torná-los instrumentos do processo de ocupação de novos territórios. ${ }^{78}$

Referências aos indígenas como trabalhadores são encontradas nas páginas do relato de viagem do missionário protestante quando o mesmo escreveu sobre os Tapirapé e os enalteceu por ter "grandes plantações de algodão, banana, inhame, etc", por serem reconhecidos por aqueles que visitam-nos pela "generosidade e simplicidade", numa atitude de admiração e surpresa pela habilidade "em fazer cestas e tecer suas redes". ${ }^{79}$ Por outro lado, ao se referir aos Kaiapó, povo atingido pelo proselitismo dominicano, Macintyre mencionou que

Durante o surto de prosperidade da borracha, milhares de aventureiros penetraram as grandes florestas à procura do líquido precioso, impelindo os índios adiante deles com seus modernos fuzis americanos, atacando suas aldeias, destruindo e matando com a maior crueldade. Os Caiapós revidaram com toda traição e astúcia de sua natureza, e o branco fluido das seringueiras muitas vezes se misturava com o vermelho do sangue dos seringueiros, tornando-se borracha vermelha.

A história completa jamais foi contada, mas o relato dos terríveis acontecimentos naquelas escuras florestas, da cobiça pela borracha branca e sangue vermelho, as lutas até a morte entre o selvagem civilizado e o civilizado selvagem, revelaria uma grande mancha escura na superioridade da qual nos gabamos, e escandalizaria a consciência cristã se fosse escrito. ${ }^{80}$

Embora observemos uma autocritica em relação à superioridade branca na narrativa protestante alusiva ao trocadilho "selvagem civilizado" e "civilizado selvagem", a traição e a astúcia são tidas como elementos da natureza indígena e não como atos de resistência de povos que secularmente passou por violentos processos de aniquilamento de seus saberes e conhecimentos ancestrais por meio do extermínio físico e por práticas de imposição da cultura branca a ser forçosamente introjetada no meio indígena como estratégia de colonização do lugar e sua gente, em benefício da sociedade nacional.

Ainda em 1920, Macintyre testemunhou o processo contínuo de expropriação territorial sofrido pelos indígenas que eram "gradativamente expulsos pelos fazendeiros invasores, cuja ganância não tem limites" ${ }^{81}$ Porém o caráter

\footnotetext{
${ }^{78}$ Ibidem, p. 156.

${ }^{79}$ MACINTYRE, op. cit., p. 50.

${ }^{80}$ Ibidem, p. 61, grifo nosso.

${ }^{81}$ Ibidem, p. 76.
} 
civilizacional de suas lentes o fez notar que os indígenas poderiam ser considerados civilizados ao usarem roupas e se misturarem aos não indígenas, serem trabalhadores e saberem utilizar ferramentas agrícolas comuns. Todavia, isto não os elevaria efetivamente à categoria "civilizados". ${ }^{82}$

\section{Considerações}

O relato de viagem de Macintyre assume uma linguagem descritiva, eurocentrada e, de especial modo, apelativa no intuito de sensibilizar pessoas, instituições e agências missionárias do seu lugar de origem a investir em tal empreendimento. A reivindicação de conversos ao protestantismo no norte goiano possibilita a viagem em si e sua posterior narrativa e publicização concretizada por este relato como ferramenta para auferir recursos humanos e materiais dentre as sociedades cristãs europeias viabilizados pelas agências missionárias as quais estavam vinculados.

A partir de então, o norte de Goiás se constituirá como lócus da ação protestantizadora implementada não apenas na Ilha do Bananal entre povos indígenas como também no meio da população goiana pelo viés da educação e da saúde. Um lugar a ser disputado com outros agentes do cristianismo como os dominicanos (que já atuavam na região desde 1896), tornando-se num espaço concorrencial, e, sobretudo, num espaço no qual se estabelecem contatos interculturais de diálogos tensos e conflitivos em algumas ocasiões, mas em outras, de trocas de conhecimentos e saberes entre as populações indígenas e os agentes missionários estrangeiros.

Artigo recebido para publicação em 26/03/2016

Artigo aprovado para publicação em 03/11/2016

${ }^{82}$ Ibidem, p. 77. 